\title{
Self-reported residential pesticide use and survival after breast cancer
}

\author{
Nicole M. Niehoff, a,*, Marilie D. Gammon ${ }^{\mathrm{a}}$, Humberto Parada Jr. ${ }^{\mathrm{b}}$, Steven D. Stellman ${ }^{\mathrm{c}}$, \\ Alfred I. Neugut ${ }^{\mathrm{c}, \mathrm{d}}$, Susan L. Teitelbaum ${ }^{\mathrm{e}}$ \\ ${ }^{a}$ Department of Epidemiology, University of North Carolina, 135 Dauer Drive, Chapel Hill, NC, 27599-7435, USA \\ ${ }^{\mathrm{b}}$ Division of Epidemiology \& Biostatistics, School of Public Health, San Diego State University, 5500 Campanile Drive, Hardy Tower Room 168, San Diego, CA, 92182, \\ USA \\ ${ }^{\mathrm{c}}$ Department of Epidemiology, Columbia University, 722 West 168th Street, New York, NY, 10032, USA \\ ${ }^{\mathrm{d}}$ Department of Medicine, Columbia University, 722 West 168th Street, New York, NY, 10032, USA \\ ${ }^{\mathrm{e}}$ Department of Environmental Medicine and Public Health, Icahn School of Medicine at Mount Sinai, 1 Gustave L. Levy Place, Box 1057, New York, NY, 10029, USA
}

\section{A R T I C L E I N F O}

\section{Keywords:}

Pesticide use

Residential

Breast cancer

Mortality

\begin{abstract}
A B S T R A C T
Introduction: Previous investigations found elevated mortality after breast cancer in association with biomarkers of persistent organochlorine pesticides in non-occupationally exposed women. We hypothesized that lifetime residential pesticide use, which includes persistent and non-persistent pesticides, would also be associated with increased mortality after breast cancer.

Methods: A population-based cohort of 1505 women with invasive or in situ breast cancer was interviewed in 1996-1997, shortly after diagnosis, about pre-diagnostic lifetime residential pesticide use. Participants were followed for mortality through 2014 (595 deaths from any cause and 236 from breast cancer, after 17.6 years of follow-up). Pesticides were examined as 15 individual categories; a group of seven used for lawn and garden purposes; a group of eight used for nuisance-pest purposes; and all combined. Cox regression was used to estimate hazard ratios (HRs) and 95\% confidence intervals (CIs) for all-cause and breast cancer-specific mortality. Modification by estrogen receptor (ER) status, body mass index, and long-term residence was examined. Results: Ever use ( $\mathrm{HR}=0.77,95 \% \mathrm{CI}=0.63-0.95)$ and higher lifetime applications (4th quartile: $\mathrm{HR}=0.62$, $95 \% \mathrm{CI}=0.47-0.81, p_{\text {trend }}=0.3$ ) of the lawn and garden group of pesticides were inversely associated with allcause mortality, compared to never use. The inverse association for lawn and garden pesticide use was limited to ER positive (vs. negative) tumors $\left(\mathrm{p}_{\text {interaction }}=0.05\right.$ ). Nuisance-pest pesticides, and all groups combined, were not associated with all-cause or breast cancer-specific mortality.

Conclusions: Contrary to our hypothesis, lifetime residential use of lawn and garden pesticides, but not all combined or nuisance-pest pesticides, was inversely associated with all-cause mortality after breast cancer.
\end{abstract}

\section{Introduction}

According to the most recent estimates in the United States (US), over 3.3 million women are living with breast cancer (National Cancer Institute, 2017) and 40,920 deaths were estimated to occur from this disease in 2018 (Siegel et al., 2018). A number of modifiable risk factors have been established for the development of breast cancer, but fewer have been identified for survival after getting the disease. Pesticides are a common environmental exposure encompassing herbicides, insecticides, rodenticides, and fungicides and their use can be modified by individual action or regulation. The Environmental Protection Agency estimated that in 1996, the first enrollment year of our study cohort, 1229 million tons of total pesticide active ingredients were used in the
US, including 130 million tons on homes and gardens (Grube et al., 2011).

Pesticides can be categorized as persistent versus non-persistent. Persistent pesticides are those that bioaccumulate in the environment and have long biological half-lives, between 5 and 15 years in humans (Genuis et al., 2016; Wolff, 1999; Wolff et al., 2005). These pesticides are also lipophilic, leading to their storage in the fat tissue of living organisms (Genuis et al., 2016). Examples of persistent pesticides include the organochlorines dichlorodiphenyltrichlorethane (DDT), chlordane, and dieldrin. Due to widespread concerns about their adverse environmental effects and growing evidence of adverse health effects, these persistent organochlorine pesticides were banned from use in the US in the 1970's and 1980's (Agency for Toxic Substances and

\footnotetext{
* Corresponding author. National Institute of Environmental Health Sciences, 111 TW Alexander Drive, Room A344, Research Triangle Park, NC, 27709, USA.

E-mail address: nicole.niehoff@nih.gov (N.M. Niehoff).
} 
Disease Registry (ATSDR), 1994; Agency for Toxic Substances and Disease Registry (ATSDR), 2002a; Agency for Toxic Substances and Disease Registry (ATSDR), 2002b). In contrast, non-persistent pesticides do not bioaccumulate in the environment, are not lipophillic, and have shorter biological half-lives, on the order of hours to a few days (Bradman and Whyatt, 2005). However, after the ban of persistent organochlorine pesticides in the US, residential use of the non-persistent pesticides rose, resulting in widespread human exposure (Centers For Disease Control). Types of non-persistent pesticides include organophosphates, carbamates, pyrethroids, herbicides, and fungicides (Centers For Disease Control).

Persistent and non-persistent pesticides may act as endocrine disruptors through their estrogenic or anti-androgenic activity and ability to affect the estrogen or aryl hydrocarbon receptors, potential biologic mechanisms in breast carcinogenesis (Chen et al., 2002; Du et al., 2010; Garey and Wolff, 1998; Ghisari et al., 2015; Go et al., 1999; Klotz et al., 1997; Medjakovic et al., 2014; Thongprakaisang et al., 2013; Welch et al., 1969). A number of studies have examined associations between pesticide exposures and breast cancer incidence, including those of selfreported residential pesticide use (El-Zaemey et al., 2014; Farooq et al., 2010; Niehoff et al., 2016; Teitelbaum et al., 2007; Zota et al., 2010), exposure to fogger truck spray (Niehoff et al., 2016; White et al., 2013), occupational or farmers' wives exposure (Duell et al., 2000; El-Zaemey et al., 2014; Engel et al., 2005, 2017), or biomarkers of organochlorine pesticides (Charlier et al., 2003; Cohn et al., 2007, 2015; Dorgan et al., 1999; Gammon et al., 2002b; Gatto et al., 2007; Hoyer et al., 2000b; Krieger et al., 1994; McCready et al., 2004; Moysich et al., 1998; Raaschou-Nielsen et al., 2005; Wolff et al., 2000; Xu et al., 2010). Overall, the results have been mixed. A few investigations, however, have captured exposure during peak use of DDT or during potentially relevant windows of susceptibility and found positive associations (Cohn et al., 2007, 2015; White et al., 2013).

Only three previous studies have examined the association of pesticide exposures with survival after a diagnosis of breast cancer. Using biomarkers of persistent, organochlorine pesticides, two observed elevated breast cancer mortality (Hoyer et al., 2000a; Parada et al., 2016), while one observed reduced breast cancer mortality (Roswall et al., 2018). We hypothesized that self-reported residential pesticide use, which includes persistent and non-persistent pesticides, would be associated with elevated breast cancer mortality among women with breast cancer. Therefore, the primary aim of the study reported here was to evaluate the association between long-term self-reported residential pesticide use and all-cause and breast cancer-specific mortality after a breast cancer diagnosis in a population-based sample of women who were subsequently followed for vital status.

\section{Material and methods}

\subsection{Study design and population}

This study utilized resources from the Long Island Breast Cancer Study Project (LIBCSP), a population-based study designed to assess environmental exposures associated with breast cancer. The parent study was initiated as a case-control study to examine associations with breast cancer development (Gammon et al., 2002a), and continued as a follow-up study to assess survival (Hoyer et al., 2000a; Parada et al., 2016). Approval for the LIBCSP was granted by the Institutional Review Board at all participating institutions.

All women in the LIBCSP were English speaking adult residents of Nassau and Suffolk counties in New York. Women with breast cancer were identified from daily or weekly contact with the pathology departments of 31 hospitals in Long Island and New York City, New York. Eligible women were diagnosed between August 1, 1996 and July 31, 1997, with first primary in situ or invasive breast cancer and whose physicians gave permission for contact. Signed informed consent and completion of the main questionnaire was obtained for 1508 (82.1\%) of women. At diagnosis, participants ranged in age from 20 to 98 years, were primarily postmenopausal (67\%), and most reported their race as white ( $94 \%$ vs. $5 \%$ black and $2 \%$ other). For the study reported here, we excluded three women who did not answer any questions from the pesticide section of the questionnaire, leaving 1505 for our ancillary study.

\subsection{Exposure assessment: residential pesticide use}

At baseline, approximately three months after diagnosis, a 2-hour structured questionnaire was administered to the women by trained examiners. Factors assessed included: reproductive, menstrual, medical, occupational, and residential histories; life course body size, physical activity, tobacco exposure, and alcohol use; and demographics.

The residential history section asked the women about pesticides used in or around their homes, yards, or gardens. Women reported on 15 individual categories of pesticides. Seven of the categories were used for lawns, gardens, or plants ("weed killers", "lawn insecticides", "chemicals for insects of diseases of trees", "pesticides on a vegetable or fruit garden", "chemicals for insects or diseases of other outdoor plants", "any other type of pesticides used outdoors", "chemicals for diseases or bugs of indoor plants"). Eight of the categories asked about products used to control nuisance pests ("ants, carpenter ants, or cockroaches", "bees or wasps", "flies or mosquitos", "moths, silverfish, or caterpillars", "mice, rats, gophers, or moles", "fleas or ticks, except on pets", "termites", "any other type of pest in your home"). For each of these categories, women were asked how many times per year and the number of years in their lifetime they, another household member, or a professional exterminator applied the products. This information was used to calculate the pre-diagnosis lifetime total number of residential pesticide applications.

Three classifications of pesticide applications were examined: overall (summed across all categories); each of the two combined groups (the seven lawn and garden pesticides combined and the eight nuisance-pest pesticides combined); and the 15 individual categories. For overall use, the total number of lifetime pesticide applications was categorized based quintiles of exposure among the 1505 women in this study. For each of the two combined groups (lawn/garden and nuisance-pest), ever use as well as quartiles of the number of lifetime applications of that group were compared to a reference of never use of that group. For each of the 15 individual categories of pesticides, ever use of that category was compared to never use of the corresponding combined group. This categorization was chosen to yield a "clean" reference group, one that includes participants unexposed to all pesticides within that group. This approach eases interpretation of the results, where the large number of categories were all examined with the same reference group. These classifications are similar to those used by Teitelbaum et al. (2007) for the related study of pesticide use and breast cancer development in the LIBCSP.

\subsection{Clinical factors}

Medical records were abstracted at two time points (at baseline and again about five years later) to assess tumor characteristics (estrogen receptor (ER) status, tumor stage, nodal involvement) and complete course of treatment (radiation therapy, chemotherapy, and hormonal therapy) for the first primary breast cancer. Tumor size was obtained from the New York State Tumor Registry.

\subsection{Follow-up for mortality}

Women with breast cancer in the LIBCSP were followed-up for mortality, and cause of death, using the National Death Index (NDI) from the National Center for Health Statistics (Centers for Disease Control and Prevention, 2014). International Statistical Classification of Disease codes 174.9 and C-50.9 were used to identify breast cancer- 
Table 1

Participant characteristics of women with breast cancer $(n=1505)$ in the Long Island Breast Cancer Study Project by total lifetime applications of pesticides.

\begin{tabular}{|c|c|c|c|c|c|}
\hline & $\begin{array}{l}\text { Quintile } 1 \text { ( }<18 \\
\text { applications) }\end{array}$ & $\begin{array}{l}\text { Quintile } 2(18-<56 \\
\text { applications) }\end{array}$ & $\begin{array}{l}\text { Quintile } 3(56-<120 \\
\text { applications) }\end{array}$ & $\begin{array}{l}\text { Quintile } 4(120-<241 \\
\text { applications) }\end{array}$ & $\begin{array}{l}\text { Quintile } 5 \text { ( } \geq 241 \\
\text { applications) }\end{array}$ \\
\hline & $\mathrm{n}(\%)$ & n $(\%)$ & $\mathrm{n}(\%)$ & $\mathrm{n}(\%)$ & n (\%) \\
\hline \multicolumn{6}{|l|}{ Age at diagnosis (years) } \\
\hline$<50$ & $101(33.8)$ & $96(31.5)$ & $82(27.2)$ & $62(20.8)$ & $65(21.6)$ \\
\hline $50-64$ & $89(29.8)$ & $114(37.4)$ & $116(38.4)$ & $134(45.0)$ & $129(42.9)$ \\
\hline$\geq 65$ & $109(36.5)$ & $95(31.2)$ & $104(34.4)$ & $102(34.2)$ & $107(35.6)$ \\
\hline \multicolumn{6}{|l|}{ Race } \\
\hline White & $267(89.6)$ & $287(94.1)$ & $288(95.7)$ & $287(96.3)$ & $280(93.3)$ \\
\hline Black & $25(8.4)$ & $12(3.9)$ & $9(3.0)$ & $8(2.7)$ & $14(4.7)$ \\
\hline Other & $6(2.0)$ & $6(2.0)$ & $4(1.3)$ & $3(1.0)$ & $6(2.0)$ \\
\hline \multicolumn{6}{|l|}{ Parity } \\
\hline Nulliparous & $51(17.1)$ & $31(10.2)$ & $52(17.2)$ & $32(10.7)$ & $31(10.3)$ \\
\hline 1 live births & $37(12.4)$ & $43(14.1)$ & $32(10.6)$ & $28(9.4)$ & $26(8.6)$ \\
\hline $2+$ births & $211(70.6)$ & $231(75.7)$ & $218(72.2)$ & 238 (79.9) & $244(81.1)$ \\
\hline \multicolumn{6}{|l|}{ Education } \\
\hline$\leq$ High school degree & $158(53.0)$ & $145(47.9)$ & $145(48.2)$ & $138(46.5)$ & $133(44.3)$ \\
\hline Some college & $66(22.2)$ & $70(23.1)$ & $80(26.6)$ & $66(22.2)$ & $77(25.7)$ \\
\hline College graduate & $33(11.1)$ & $40(13.2)$ & $37(12.3)$ & $45(15.2)$ & $36(12.0)$ \\
\hline Post-college & $41(13.8)$ & $48(15.8)$ & $39(13.0)$ & $48(16.2)$ & $54(18.0)$ \\
\hline \multicolumn{6}{|l|}{ Marital status } \\
\hline Never married & $23(7.7)$ & $10(3.3)$ & $9(3.0)$ & $9(3.0)$ & $11(3.7)$ \\
\hline Ever married & $276(92.3)$ & $295(96.7)$ & $293(97.0)$ & $289(97.0)$ & $289(96.3)$ \\
\hline \multicolumn{6}{|c|}{ Length of residence (years) } \\
\hline$<15$ & $61(21.3)$ & $50(17.1)$ & $34(11.5)$ & $22(7.5)$ & $25(8.5)$ \\
\hline$\geq 15$ & $226(78.8)$ & $243(82.9)$ & $262(88.5)$ & $271(92.5)$ & $268(91.5)$ \\
\hline \multicolumn{6}{|c|}{ BMI at diagnosis $\left(\mathrm{kg} / \mathrm{m}^{2}\right)$} \\
\hline$<25.0$ & $142(48.5)$ & $148(49.0)$ & $144(47.8)$ & 125 (42.7) & $124(41.5)$ \\
\hline $25.0-29.9$ & $86(29.4)$ & $99(32.8)$ & $91(30.2)$ & $103(35.2)$ & $97(32.4)$ \\
\hline$\geq 30.0$ & $65(22.2)$ & $55(18.2)$ & $66(21.9)$ & $65(22.2)$ & $78(26.1)$ \\
\hline \multicolumn{6}{|l|}{ ER status } \\
\hline ER- & $51(26.2)$ & $66(30.6)$ & $42(22.5)$ & $53(28.5)$ & $51(24.4)$ \\
\hline $\mathrm{ER}+$ & 144 (73.6) & $150(69.4)$ & 145 (77.5) & $133(71.5)$ & $158(75.6)$ \\
\hline \multicolumn{6}{|l|}{ Stage } \\
\hline In situ & $46(15.4)$ & 48 (15.7) & 59 (19.5) & $48(16.1)$ & $34(11.3)$ \\
\hline Invasive & $253(84.6)$ & $257(84.3)$ & $243(80.5)$ & $250(83.9)$ & 267 (88.7) \\
\hline
\end{tabular}

specific deaths. Follow-up after the date of diagnosis in 1996-1997 continued until December 31, 2014. Among the 1505 women with breast cancer included in the study reported here, there were 595 deaths from any cause (all-cause mortality) and 236 attributed to breast cancer (breast cancer-specific mortality).

\subsection{Statistical analysis}

We examined the distribution of characteristics among the 1505 women with breast cancer, with participants stratified by total lifetime number of pesticide applications (dichotomized at the median). To assess associations between each of the pesticide classifications and allcause and breast cancer-specific mortality, we constructed Cox proportional hazards models to estimate hazard ratios (HRs) and 95\% confidence intervals (CIs). The proportional hazards assumption was assessed using an interaction term between covariates and time. No violations of the assumption were observed.

Potential confounders were determined using a directed acyclic graph (DAG) (Greenland et al., 1999; Shrier and Platt, 2008). All models were adjusted for the minimally sufficient adjustment set that was determined from the DAG: age, parity, education ( $\leq$ high school degree, some college, college graduate, post-college degree), race (white, black, other), and marital status (ever/never). In this population, tumor characteristics (stage, tumor size, nodal involvement) and treatment (radiation therapy, chemotherapy, hormonal therapy) may be considered on the causal pathway between residential pesticide exposure and mortality, given that we previously reported a positive association between residential pesticide use and breast cancer development in the same study population (Teitelbaum et al., 2007). The assumption is that pesticides cause breast cancer and, therefore, determine the tumor characteristics and subsequent treatment regimen, which in turn influence mortality. Thus, we did not include tumor characteristics and treatment in the adjustment set, because to do so would result in biased effect estimates (Greenland et al., 1999; Shrier and Platt, 2008). Additionally, these characteristics are not on a confounding path because ER status, tumor stage, nodal involvement, or treatment choice could not have influenced the exposure, a woman's lifetime pesticide use. Therefore, adjustment as confounders was not warranted.

Potential effect-measure modifiers of the pesticide-mortality association included: length of residence in the interview home $(\geq 15$ vs. $<15$ years); BMI ( $\geq 25$ vs. $<25 \mathrm{~kg} / \mathrm{m}^{2}$ ); and ER status (positive vs. negative). Although we did not consider tumor stage as a confounder, given the importance of stage on breast cancer survival, we did consider whether tumor size ( $\geq 2$ vs. $<2 \mathrm{~mm}$ ) and nodal involvement (yes vs. no), surrogates of tumor stage that were available in the LIBCSP, modified the associations. To assess modification on the multiplicative scale, stratum-specific HRs were estimated along with the ratio of hazard ratios (RHRs) and corresponding 95\% CIs; we also conducted log likelihood ratio tests (LRT) from nested models with and without interaction terms. To assess modification on the additive scale, singlereferent models were used to compute interaction contrast ratios (ICRs) and corresponding 95\% CIs (de Mutsert et al., 2009; Hosmer and Lemeshow, 1992; Li and Chambless, 2007; Rothman et al., 2008).

The primary analysis examined associations for mortality outcomes among all women with breast cancer, but a sensitivity analysis was conducted by restricting the analyses to invasive cases alone. All analyses were conducted using SAS 9.4 (SAS Institute Inc., Cary, NC). 
Table 2

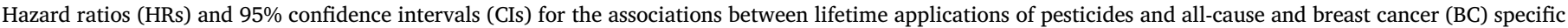
mortality in the Long Island Breast Cancer Study Project (LIBCSP), 1996-1997.

\begin{tabular}{|c|c|c|c|c|c|c|c|}
\hline & \multicolumn{3}{|c|}{ Lifetime applications (no.) } & \multirow[t]{2}{*}{ All-cause deaths (no.) } & \multirow{2}{*}{$\frac{\text { All-cause mortality }}{\text { HR }(95 \% \mathrm{CI})^{\mathrm{a}}}$} & \multirow[t]{2}{*}{ BC deaths (no.) } & \multirow{2}{*}{$\frac{\text { BC-specific mortality }}{\text { HR }(95 \% \mathrm{CI})^{\mathrm{a}}}$} \\
\hline & Minimum & Median & Maximum & & & & \\
\hline \multicolumn{8}{|c|}{ All pest groups combined } \\
\hline Quintile 1 & 0 & 6 & 17 & 133 & 1.00 & 50 & 1.00 \\
\hline Quintile 2 & 18 & 34 & 55 & 117 & $0.99(0.77,1.28)$ & 48 & $1.02(0.68,1.52)$ \\
\hline Quintile 3 & 56 & 81 & 119 & 118 & $0.96(0.74,1.23)$ & 51 & $1.12(0.75,1.67)$ \\
\hline Quintile 4 & 120 & 167 & 240 & 108 & $0.88(0.68,1.15)$ & 41 & $0.92(0.60,1.40)$ \\
\hline \multirow[t]{2}{*}{ Quintile 5} & 241 & 475 & 20,834 & 116 & $0.88(0.68,1.13)$ & 44 & $0.95(0.63,1.44)$ \\
\hline & & & & & $p$ trend $=0.4$ & & $p$ trend $=0.5$ \\
\hline \multicolumn{8}{|c|}{ Lawn and garden combined group } \\
\hline \multicolumn{4}{|c|}{ Never used lawn and garden pesticides } & 129 & 1.00 & 44 & 1.00 \\
\hline \multicolumn{4}{|c|}{ Ever used lawn and garden pesticides } & 456 & $0.77(0.63,0.95)$ & 189 & $0.87(0.62,1.23)$ \\
\hline Quartile 1 & 1 & 5 & 15 & 132 & $0.84(0.66,1.08)$ & 54 & $0.90(0.60,1.36)$ \\
\hline Quartile 2 & 16 & 28 & 42 & 110 & $0.74(0.57,0.96)$ & 45 & $0.83(0.54,1.28)$ \\
\hline Quartile 3 & 43 & 71 & 110 & 121 & $0.91(0.70,1.18)$ & 55 & $1.10(0.72,1.66)$ \\
\hline \multirow[t]{2}{*}{ Quartile 4} & 112 & 176 & 20,820 & 93 & $0.62(0.47,0.81)$ & 35 & $0.65(0.41,1.04)$ \\
\hline & & & & & $p$ trend $=0.3$ & & $p$ trend $=0.4$ \\
\hline \multicolumn{8}{|c|}{ Nuisance-pest combined group } \\
\hline \multicolumn{4}{|c|}{ Never used nuisance-pest pesticides } & 50 & 1.00 & 20 & 1.00 \\
\hline \multicolumn{4}{|c|}{ Ever used nuisance-pest pesticides } & 535 & $0.90(0.67,1.21)$ & 213 & $0.77(0.48,1.23)$ \\
\hline Quartile 1 & 1 & 3 & 8 & 149 & $0.93(0.67,1.29)$ & 58 & $0.81(0.48,1.36)$ \\
\hline Quartile 2 & 9 & 18 & 38 & 121 & $0.82(0.59,1.16)$ & 53 & $0.70(0.41,1.19)$ \\
\hline Quartile 3 & 39 & 61 & 108 & 130 & $0.90(0.64,1.25)$ & 50 & $0.73(0.43,1.25)$ \\
\hline \multirow[t]{2}{*}{ Quartile 4} & 109 & 330 & 7851 & 135 & $0.96(0.68,1.34)$ & 52 & $0.84(0.49,1.44)$ \\
\hline & & & & & $p$ trend $=0.9$ & & $p$ trend $=0.9$ \\
\hline
\end{tabular}

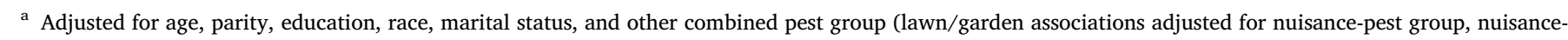
pest associations adjusted for lawn/garden group).

\section{Results}

Among this population-based sample of women with breast cancer, those with higher total pre-diagnosis lifetime pesticide use were more likely to have two or more live births ( $81.1 \%$ in quintile 5 vs. $70.6 \%$ in quintile 1$)$, have a college degree or higher $(30.0 \%$ in quintile 5 vs. $24.8 \%$ in quintile 1), have lived in their current residence for 15 or more years $(91.5 \%$ in quintile 5 vs. $78.8 \%$ in quintile 1$)$, and have a BMI $\geq 30.0 \mathrm{~kg} / \mathrm{m}^{2}(22.2 \%$ in quintile 5 vs. $22.2 \%$ in quintile 1$)$ (Table 1).

There was little or no association between all pesticides combined and all-cause or breast cancer-specific mortality (Table 2). However, ever (vs. never) use of lawn and garden pesticides was associated with a reduced rate of all-cause mortality ( $\mathrm{HR}=0.77 ; 95 \% \mathrm{CI}=0.63-0.95$ ). Similarly, quartiles 2 and 4 of pre-diagnosis lifetime applications of lawn and garden were inversely associated with all-cause mortality compared to never use $(\mathrm{HR}=0.74 ; 95 \% \mathrm{CI}=0.57-0.96$; $\mathrm{HR}=0.62$; $95 \% \mathrm{CI}=0.47-0.81$, respectively; $p_{\text {-trend }}=0.3$ ). There was also a suggestive inverse association between the fourth quartile of lawn and garden applications and breast cancer-specific mortality $(\mathrm{HR}=0.65$; $95 \% \mathrm{CI}=0.41-1.04)$. There was little to no association between ever use, or quartiles of pre-diagnosis lifetime applications, of the nuisancepest pesticide group, and either all-cause or breast cancer-specific mortality.

When considering associations between the 15 individual pesticide categories and all-cause and breast cancer-specific mortality (Table 3), ever use for many of the individual lawn and garden pesticides was associated with a reduced rate of all-cause mortality compared to never use of any lawn/garden pesticides. This was found for pesticides used for weeds, lawn insects, insects or diseases of trees, and any other type used outdoors. HR point estimates for these categories ranged from 0.45 to 0.73 . There was little to no association between individual lawn/ garden pesticides and breast cancer-specific mortality, with the exception of suggestive inverse associations for the lawn insect category. Individual categories of nuisance-pest pesticides did not appear to be associated with all-cause or breast cancer-specific mortality.
As shown in Table 4, lawn and garden pesticide applications were associated with reduced all-cause mortality among women with ER positive tumors ( $\mathrm{HR}=0.66$; $95 \% \mathrm{CI}=0.52-0.84)$, but there was no association among women with ER negative tumors (HR $=1.03$; $95 \%$ $\mathrm{CI}=0.71-1.49)\left(\mathrm{LRT} p_{\text {multiplicative interaction }}=0.05\right)$. The RHR for the heterogeneity was 0.64 ( $95 \% \mathrm{CI}=0.42-0.99)$. ER status did not modify associations for overall pesticides or nuisance-pest pesticides with allcause mortality. Additionally, there was no modification by ER status for any pesticide categories with breast cancer-specific mortality (Supplemental Table 1). Neither tumor size (Supplemental Tables 2 and 3) nor nodal involvement (Supplemental Tables 4 and 5) modified the associations between any pesticide group and all-cause or breast cancer-specific mortality. Finally, there was no evidence of modification by BMI or length of residence for any pesticide categories with either all-cause or breast cancer-specific mortality (data not shown).

In sensitivity analyses, where we restricted our models to women with invasive breast cancer, results did not differ substantially from those shown that included both women with invasive and in situ breast cancer (data not shown).

\section{Discussion}

Contrary to our study hypothesis, ever use and higher number of pre-diagnosis lifetime applications of lawn and garden pesticides were inversely associated with all-cause mortality. Some individual categories of lawn and garden pesticides were also inversely associated with all-cause mortality. Further, the inverse association between lawn/ garden pesticides and all-cause mortality was observed for ER positive tumors only. Lawn pesticides did not appear to be associated with breast cancer-specific mortality, although precision was reduced. Conversely, all pest groups combined and nuisance-pest pesticides were not associated with all-cause or breast cancer-specific mortality.

Our population-based cohort study of women with breast cancer is the first to examine self-reported residential pesticide use with survival after breast cancer, although a previous LIBCSP study did report on the self-reported residential pesticides with breast cancer development 
Table 3

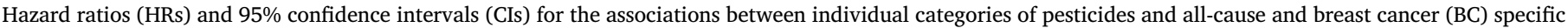
mortality in the Long Island Breast Cancer Study Project (LIBCSP), 1996-1997.

\begin{tabular}{|c|c|c|c|c|}
\hline \multirow[t]{2}{*}{ Ever used pesticides for individual pest category } & \multirow[t]{2}{*}{ All-cause deaths (no.) } & All-cause mortality & \multirow[t]{2}{*}{ BC deaths (no.) } & \multirow{2}{*}{$\frac{\text { BC-specific mortality }}{\text { HR }(95 \% \mathrm{CI})^{\mathrm{a}, \mathrm{b}}}$} \\
\hline & & HR $(95 \% \mathrm{CI})^{\mathrm{a}, \mathrm{b}}$ & & \\
\hline Never used any lawn and garden pesticides & 129 & 1.00 & 44 & 1.00 \\
\hline Weeds & 392 & $0.75(0.61,0.92)$ & 164 & $0.84(0.59,1.19)$ \\
\hline Lawn insects & 270 & $0.73(0.59,0.91)$ & 110 & $0.78(0.54,1.13)$ \\
\hline Insects or diseases of trees & 184 & $0.73(0.58,0.93)$ & 77 & $0.84(0.57,1.25)$ \\
\hline Vegetable or fruit garden pests & 115 & $0.91(0.70,1.19)$ & 48 & $1.01(0.66,1.55)$ \\
\hline Insects or diseases of other outdoor plants & 96 & $0.83(0.63,1.10)$ & 43 & $1.03(0.66,1.61)$ \\
\hline Any other type used outdoors & 17 & $0.45(0.27,0.76)$ & 6 & $0.48(0.20,1.15)$ \\
\hline Diseases or bugs of indoor plants & 38 & $0.80(0.55,1.16)$ & 17 & $0.93(0.52,1.68)$ \\
\hline Never used any nuisance-pest pesticides & 50 & 1.00 & 20 & 1.00 \\
\hline Ants, carpenter ants, or cockroaches & 425 & $0.87(0.65,1.18)$ & 172 & $0.74(0.46,1.20)$ \\
\hline Bees or wasps & 215 & $0.87(0.63,1.19)$ & 88 & $0.76(0.46,1.25)$ \\
\hline Flies or mosquitos & 123 & $0.95(0.67,1.33)$ & 52 & $0.84(0.49,1.42)$ \\
\hline Moths, silverfish, or caterpillars & 132 & $0.87(0.62,1.22)$ & 62 & $0.84(0.50,1.42)$ \\
\hline Mice, rats, gophers, or moles & 81 & $0.77(0.54,1.10)$ & 36 & $0.72(0.41,1.26)$ \\
\hline Fleas or ticks, except on pets & 129 & $0.96(0.68,1.34)$ & 62 & $0.85(0.50,1.44)$ \\
\hline Termites & 275 & $0.89(0.65,1.21)$ & 110 & $0.79(0.48,1.29)$ \\
\hline Any other type of pest in your home & 17 & $0.90(0.52,1.58)$ & 10 & $1.12(0.51,2.43)$ \\
\hline
\end{tabular}

a Adjusted for age, parity, education, race, marital status, and other combined pest group (lawn/garden pesticides adjusted for nuisance-pest group, nuisance-pest pesticides adjusted for lawn/garden group).

b Each hazard ratio was determined from a separate model. A three level indicator variable was used with a common reference group: never used the combined category of pesticides (referent), used a pesticide in the combined group but not that individual category, used the individual category (index).

Table 4

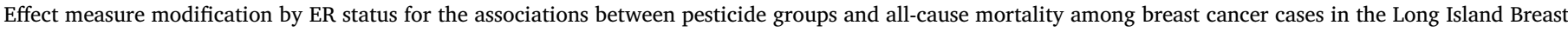
Cancer Study Project, 1996-1997.

\begin{tabular}{|c|c|c|c|c|c|c|c|c|}
\hline ER status & $\begin{array}{l}\text { Applications of } \\
\text { pesticide group }\end{array}$ & Deaths & Censored & $\begin{array}{l}\text { Single referent HRs } \\
(95 \% \mathrm{CI})^{\mathrm{a}}\end{array}$ & $\begin{array}{l}\text { Additive ICR } \\
(95 \% \mathrm{CI})\end{array}$ & $\begin{array}{l}\text { Stratified HRs } \\
(95 \% \mathrm{CI})^{\mathrm{a}}\end{array}$ & $\begin{array}{l}\text { Ratio of stratified HRs } \\
(95 \% \mathrm{CI})\end{array}$ & $P_{\text {interaction }}$ \\
\hline \multicolumn{9}{|c|}{ Overall pesticides } \\
\hline \multirow[t]{2}{*}{$\mathrm{ER}+$} & $>$ median & 147 & 215 & $0.74(0.54,1.00)$ & $0.03(-0.36,0.42)$ & $0.98(0.78,1.23)$ & $1.03(0.67,1.58)$ & 0.9 \\
\hline & $\leq$ median & 170 & 194 & $0.75(0.55,1.02)$ & & 1.00 & & \\
\hline \multirow[t]{2}{*}{ ER- } & $>$ median & 55 & 69 & $0.96(0.66,1.39)$ & & $0.96(0.66,1.39)$ & & \\
\hline & $\leq$ median & 60 & 78 & 1.00 & & 1.00 & & \\
\hline \multicolumn{9}{|c|}{ Lawn pesticides } \\
\hline \multirow[t]{2}{*}{$\mathrm{ER}+$} & $>$ median & 126 & 230 & $0.61(0.44,0.85)$ & $-0.34(-0.82,0.13)$ & $0.66(0.52,0.84)$ & $0.64(0.42,0.99)$ & 0.05 \\
\hline & $\leq$ median & 191 & 179 & $0.93(0.68,1.23)$ & & 1.00 & & \\
\hline \multirow[t]{2}{*}{ ER- } & $>$ median & 57 & 72 & $1.03(0.71,1.49)$ & & $1.03(0.71,1.49)$ & & \\
\hline & $\leq$ median & 58 & 75 & 1.00 & & 1.00 & & \\
\hline \multicolumn{9}{|c|}{ Nuisance-pest pesticides } \\
\hline \multirow[t]{2}{*}{$\mathrm{ER}+$} & $>$ median & 157 & 210 & $0.91(0.66,1.26)$ & $-0.21(-0.71,0.30)$ & $1.10(0.88,1.38)$ & $0.85(0.55,1.32)$ & 0.5 \\
\hline & $\leq$ median & 160 & 199 & $0.83(0.60,1.14)$ & & 1.00 & & \\
\hline \multirow[t]{2}{*}{ ER- } & $>$ median & 63 & 69 & $1.29(0.89,1.88)$ & & $1.29(0.89,1.88)$ & & \\
\hline & $\leq$ median & 52 & 78 & 1.00 & & 1.00 & & \\
\hline
\end{tabular}

a Adjusted for age, parity, education, race, marital status, and other pesticide group.

(Teitelbaum et al., 2007). Three previous studies of breast cancer mortality and pesticides examined biomarkers of the persistent organochlorine pesticides (Hoyer et al., 2000a; Parada et al., 2016; Roswall et al., 2018). In the same LIBCSP population, the highest tertile of blood p,p'-DDT was associated with all-cause (HR $=2.19 ; 95 \% \mathrm{CI}$ : $1.02-4.67)$ and breast cancer-specific mortality ( $\mathrm{HR}=2.72 ; 95 \% \mathrm{CI}$ : $1.04-7.13) 5$ years after diagnosis (Parada et al., 2016). Blood p,p'-dichlorodiphenyldichloroethylene (DDE), the metabolite of p,p'-DDT and a known anti-androgen (Kelce et al., 1995), was inversely associated with all-cause mortality (HR $=0.66$; 95\% CI: 0.44-0.99) (Parada et al., 2016). In a study of blood biomarker organochlorines and breast cancer survival conducted in Denmark, dieldrin was associated with increased all-cause ( $\mathrm{RR}=2.78 ; 95 \% \mathrm{CI}: 1.38-5.59)$ and breast cancer-specific mortality ( $R R=2.61 ; 95 \%$ CI: 0.97-7.01) (Hoyer et al., 2000a). Suggestive positive associations were also found for p,p'-DDT, but the confidence intervals were imprecise due to a smaller sample size. One study measured organochlorines in adipose tissue (Roswall et al., 2018); p,p'-DDT and p,p'-DDE were inversely associated with all-cause mortality (linear mortality rate ratio $(\mathrm{MRR})=0.89$; 95\% CI: 0.69-1.00 and linear MRR $=0.82$; 95\% CI: 0.69-0.98, respectively), while dieldrin was associated with increased mortality (linear MRR $=1.22 ; 95 \%$ CI: 1,05-1.41).

In contrast to these studies, our study reported here assessed prediagnosis lifetime exposure to residential pesticides. Some LIBCSP participants who were older at enrollment may have had organochlorines like DDT applied residentially before those pesticides were banned in the 1970's. However, many of the years of lifetime pesticide application, particularly in the years closer to their breast cancer diagnosis in 1996 and 1997, which could be more relevant for influencing mortality after breast cancer (Parada et al., 2016), would have been in the period after the ban and likely instead captured non-persistent pesticides. In 1996 the most commonly used pesticide active 
ingredients used in the home and garden sector were the herbicides 2,4dichlorophenoxyacetic acid (2,4-D), glyphosate, dicamba, and mecoprop (MCPP) (Aspelin and Grube, 1999), all of which are considered non-persistent (Centers For Disease Control; International Agency for Research on Cancer (IARC), 2016; Vighi et al., 2017).

Biologically, two in vitro studies have examined the effects of a variety of non-persistent pesticides on the ERa, androgen receptor, or aryl hydrocarbon receptor and found that a majority of the pesticides exhibited agonistic effects on these receptors, and concluded that the pesticides can act as endocrine disruptors (Ghisari et al., 2015; Medjakovic et al., 2014). Glyphosate, the most commonly used herbicide in the US (Grube et al., 2011), was shown to alter ER $\alpha$ and $\beta$ expression, and demonstrate estrogenic activity in hormone-dependent breast cancer cells (Thongprakaisang et al., 2013). Carbamate insecticides demonstrated weak activation of estrogen or progesterone reported gene activity, but acted as antagonists in the presence of $17 \beta$-estradiol or progesterone in a study using breast cancer cell lines (Klotz et al., 1997). In two studies, two of four pyrethroid insecticides exhibited estrogenicity (Garey and Wolff, 1998; Go et al., 1999) and all four induced cell proliferation of MCF-7 breast cancer cells (Go et al., 1999). This was consistent with an additional study that found all of the pyrethroids examined induced MCF-7 proliferation and demonstrated an ability to block the binding of estradiol to the ER (Chen et al., 2002). In contrast, one study found that, while four of 11 compounds were ER agonists, six acted anti-estrogenically in vitro (Du et al., 2010). Biologically, persistent pesticides have also demonstrated endocrine disrupting effects (Zhuang et al., 2012). DDT, dieldrin, and chlordane, have demonstrated estrogenic activity (Soto et al., 1994; Welch et al., 1969), while DDE is an anti-androgen (Kelce et al., 1995). Additionally, persistent pesticides may induce cell proliferation through interactions with the estrogen receptors (Zhuang et al., 2012), may affect cell invasiveness (Pestana et al., 2015), or may be stored in the adipose tissue surrounding the tumor and affect the tumor microenvironment (Munoz-de-Toro et al., 2006).

These experimental studies demonstrate the endocrine disrupting potential of non-persistent and persistent pesticides, many of which may be ER agonists. Therefore, reasons for our observation of an inverse association for lawn and garden pesticides, but not all pesticides combined or nuisance-pest pesticides, with all-cause mortality after a breast cancer diagnosis reported here are unclear. However, there is evidence of both anti-estrogenic and estrogenic agents being associated with increased survival after breast cancer and suggests that the mechanisms linking them to breast cancer survival are complex. For example, diethylstilbestrol (DES), a high-dose estrogen, was previously used as an endocrine treatment for breast cancer in postmenopausal women and had similar efficacy as tamoxifen, an anti-estrogen in breast cells, which is used today (Ingle, 2002; Ingle et al., 1981). Additionally, although we adjusted for education as a marker of socioeconomic status (SES), it is possible that there is residual confounding by a component of SES that was not captured fully. For example, since only the lawn and garden pesticides were associated with survival, perhaps the associations reflect the ability of women to reside in a house that contains a lawn or garden, which could correlate with other factors for better survival. However, this study was conducted using a population from Long Island, New York where the majority of the houses are suburban and likely have lawns.

Our study has several limitations that should be considered for the interpretation of our results. Although the LIBCP questionnaire was comprehensive in collecting information on 15 categories of pesticides, it assessed general categories based on what the pesticide was used for, but not the names of specific pesticides used. This is because during the pilot phase of an earlier draft questionnaire, respondents who were residents of Long Island, were unable to remember the exact names of pesticides used in the past, but could recall the reasons for using these chemicals (unpublished data). The implications are that multiple different pesticides may have been used for the same category, or a single pesticide could have been used in multiple categories (Teitelbaum et al., 2007). For example, a single carbamate insecticide may have been used for "ants, carpenter ants, or cockroaches" and also for "termites." Another limitation is that we cannot exclude the possibility of exposure misclassification due to a woman's ability to recall long-term pesticide use. This was less of a concern when we considered ever/ never use, compared to the lifetime number of applications, which required women to report duration and frequency of use. Any potential misclassification based on the ability to recall pesticide use would have been non-differential by outcome status because the information was reported prior to mortality. Additionally, we assessed pesticide use with a lifetime measure of number of applications as well as ever/never, but we did not have information on the specific time period that the pesticides were used by women (Teitelbaum et al., 2007). Nonetheless, it is likely that the lifetime applications measures are adequate for ranking women as lower vs. higher use. We also didn't consider how much women continued to use pesticides after their diagnosis, which could be a more relevant window of exposure for mortality and should be examined in future studies that have information on post-diagnosis use. However, other studies in this population have found associations between pre/at-diagnosis exposures and survival after breast cancer (Cleveland et al., 2007, 2012; Khankari et al., 2015; Parada et al., 2017; Wang et al., 2018). Use of a few individual categories of pesticides (e.g. "any other type used outdoors") were less common and resulted in smaller sample sizes and less precise estimates.

Despite these limitations, this study also had strengths. To our knowledge, ours is the first study to examine self-reported residential pesticide use with survival after breast cancer, addressing a potentially important public health concern, given the fact that residential pesticides are common exposures. Participants are population-based, enhancing the generalizability of our results. Our outcome measures, allcause and breast cancer-specific mortality, are of high quality because they were ascertained using the NDI, which has high sensitivity and specificity (Rich-Edwards et al., 1994). Additionally, we used a comprehensive, interviewer-administered questionnaire to assess three groups and 15 individual categories of pesticides; this is a more detailed assessment of these exposures than is typically encountered in epidemiologic studies. Another strength was that participants were residentially stable; $84 \%$ of the women had lived in their baseline residence for at least 15 years. Residentially stable women may have encountered similar pest problems over time, improving their recall of lifetime pesticide use (Teitelbaum et al., 2007).

After a breast cancer diagnosis, women may be concerned that their prognosis may be influenced by their past exposure to potentially harmful environmental pollutants. Thus, it may be reassuring that the results of this first study indicate that pre-diagnosis lifetime residential pesticide use did not impact their survival adversely. Instead, contrary to our study hypothesis, we observed an inverse association among lawn and garden pesticides with all-cause mortality, and no association with all pesticide groups combined or nuisance-pest pesticides. Future studies are needed to confirm our findings, and should also consider exposures after diagnosis and potential heterogeneity by race.

\section{Conflicts of interest}

None.

\section{Sources of funding}

This work was supported in part by grants from the National Cancer Institute and the National Institute of Environmental Health Sciences (UO1CA/ES66572, UO1CA66572, T32ES007018, and T32CA057726).

\section{Appendix A. Supplementary data}

Supplementary data to this article can be found online at https:// doi.org/10.1016/j.ijheh.2019.07.010. 


\section{References}

Agency for Toxic Substances and Disease Registry (ATSDR), 1994. Toxicological Profile for Chlordane. US Department of Health and Human Services, Atlanta, GA.

Agency for Toxic Substances and Disease Registry (ATSDR), 2002a. Toxicological Profile for Aldrin/dieldrin. US Department of Health and Human Services, Atlanta, GA.

Agency for Toxic Substances and Disease Registry (ATSDR), 2002b. Toxicological Profile for DDT, DDE, and DDD. US Department of Health and Human Services, Atlanta, GA.

Aspelin, A., Grube, A., 1999. Pesticides Industry Sales and Usage: 1996 and 1997 Market Estimates. Environmental Protection Agency, Washington, DC.

Bradman, A., Whyatt, R.M., 2005. Characterizing exposures to nonpersistent pesticides during pregnancy and early childhood in the National Children's Study: a review of monitoring and measurement methodologies. Environ. Health Perspect. 113, 1092-1099.

Centers For Disease Control, Glossary of Classes of Non-persistent Pesticides. Department of Health and Human Services, Atlana, GA.

Centers for Disease Control and Prevention, 2014. National Death Index.

Charlier, C., et al., 2003. Breast cancer and serum organochlorine residues. Occup. Environ. Med. 60, 348-351.

Chen, H., et al., 2002. Estrogenicity of organophosphorus and pyrethroid pesticides. J. Toxicol. Environ. Health 65, 1419-1435.

Cleveland, R.J., et al., 2007. Weight gain prior to diagnosis and survival from breast cancer. Cancer Epidemiol. Biomark. Prev. 16, 1803-1811.

Cleveland, R.J., et al., 2012. Influence of prediagnostic recreational physical activity on survival from breast cancer. Eur. J. Cancer Prev. 21, 46-54.

Cohn, B.A., et al., 2015. DDT exposure in utero and breast cancer. J. Clin. Endocrinol, Metab. 100, 2865-2872.

Cohn, B.A., et al., 2007. DDT and breast cancer in young women: new data on the significance of age at exposure. Environ. Health Perspect. 115, 1406-1414.

de Mutsert, R., et al., 2009. The effect of joint exposures: examining the presence of interaction. Kidney Int. 75, 677-681.

Dorgan, J.F., et al., 1999. Serum organochlorine pesticides and PCBs and breast cancer risk: results from a prospective analysis (USA). Cancer Causes Control 10, 1-11.

Du, G., et al., 2010. Assessing hormone receptor activities of pyrethroid insecticides and their metabolites in reporter gene assays. Toxicol. Sci. 116, 58-66.

Duell, E.J., et al., 2000. A population-based case-control study of farming and breast cancer in North Carolina. Epidemiology 11, 523-531.

El-Zaemey, S., et al., 2014. Household and occupational exposure to pesticides and risk of breast cancer. Int. J. Environ. Health Res. 24, 91-102.

Engel, L.S., et al., 2005. Pesticide use and breast cancer risk among farmers' wives in the agricultural health study. Am. J. Epidemiol. 161, 121-135.

Engel, L.S., et al., 2017. Insecticide use and breast cancer risk among farmers' wives in the agricultural health study. Environ. Health Perspect. 125, 097002.

Farooq, U., et al., 2010. Self-reported exposure to pesticides in residential settings and risk of breast cancer: a case-control study. Environ. Health 9, 30.

Gammon, M.D., et al., 2002a. The Long Island Breast Cancer Study Project: description of a multi-institutional collaboration to identify environmental risk factors for breast cancer. Breast Canc. Res. Treat. 74, 235-254.

Gammon, M.D., et al., 2002b. Environmental toxins and breast cancer on Long Island. II. Organochlorine compound levels in blood. Cancer Epidemiol. Biomark. Prev. 11, 686-697.

Garey, J., Wolff, M.S., 1998. Estrogenic and antiprogestagenic activities of pyrethroid insecticides. Biochem. Biophys. Res. Commun. 251, 855-859.

Gatto, N.M., et al., 2007. Serum organochlorines and breast cancer: a case-control study among African-American women. Cancer Causes Control 18, 29-39.

Genuis, S., et al., 2016. Human elimination of organochlorine pesticides: blood, urine, and sweat study. BioMed Res. Int., 16246432016.

Ghisari, M., et al., 2015. Effects of currently used pesticides and their mixtures on the function of thyroid hormone and aryl hydrocarbon receptor in cell culture. Toxicol. Appl. Pharmacol. 284, 292-303.

Go, V., et al., 1999. Estrogenic potential of certain pyrethroid compounds in the MCF-7 human breast carcinoma cell line. Environ. Health Perspect. 107, 173-177.

Greenland, S., et al., 1999. Causal diagrams for epidemiologic research. Epidemiology 10, 37-48.

Grube, A., et al., 2011. Pesticide Industry Sales and Usage: 2006 and 2007 Market Estimates. Environmental Protection Agency, Washington, DC.

Hosmer, D.W., Lemeshow, S., 1992. Confidence interval estimation of interaction. Epidemiology 3, 452-456.

Hoyer, A.P., et al., 2000a. Organochlorine exposure and breast cancer survival. J. Clin. Epidemiol. 53, 323-330.

Hoyer, A.P., et al., 2000b. Repeated measurements of organochlorine exposure and breast cancer risk (Denmark). Cancer Causes Control 11, 177-184.

Ingle, J.N., 2002. Estrogen as therapy for breast cancer. Breast Cancer Res. 4, 133-136. Ingle, J.N., et al., 1981. Randomized clinical trial of diethylstilbestrol versus tamoxifen in postmenopausal women with advanced breast cancer. N. Engl. J. Med. 304, 16-21.

International Agency for Research on Cancer (IARC), 2016. Malathion. IARC
Momographs on the Evaluation of Carcinogenic Risks to Humans, Lyon, France.

Kelce, W.R., et al., 1995. Persistent DDT metabolite p,p'-DDE is a potent androgen receptor antagonist. Nature 375, 581-585.

Khankari, N.K., et al., 2015. Dietary Intake of Fish, Polyunsaturated Fatty Acids, and Survival after Breast Cancer: A Population-Based Follow-Up Study on Long Island. vol. 121. Cancer, New York, pp. 2244-2252.

Klotz, D.M., et al., 1997. Inhibition of 17 beta-estradiol and progesterone activity in human breast and endometrial cancer cells by carbamate insecticides. Life Sci. 60 $1467-1475$.

Krieger, N., et al., 1994. Breast cancer and serum organochlorines: a prospective study among white, black, and Asian women. J. Natl. Cancer Inst. 86, 589-599.

Li, R., Chambless, L., 2007. Test for additive interaction in proportional hazards models. Ann. Epidemiol. 17, 227-236.

McCready, D., et al., 2004. Breast tissue organochlorine levels and metabolic genotypes in relation to breast cancer risk Canada. Cancer Causes Control 15, 399-418.

Medjakovic, S., et al., 2014. Effect of nonpersistent pesticides on estrogen receptor, androgen receptor, and aryl hydrocarbon receptor. Environ. Toxicol. 29, 1201-1216.

Moysich, K.B., et al., 1998. Environmental organochlorine exposure and postmenopausal breast cancer risk. Cancer Epidemiol. Biomark. Prev. 7, 181-188.

Munoz-de-Toro, M., et al., 2006. Estrogenic microenvironment generated by organochlorine residues in adipose mammary tissue modulates biomarker expression in ERalpha-positive breast carcinomas. Breast Cancer Res. 8, R47.

National Cancer Institute, 2017. Cancer Stat Facts: Female Breast Cancer, vol. 2017 Surveillance, Epidemiology, and End Results Program (SEER).

Niehoff, N.M., et al., 2016. Childhood and adolescent pesticide exposure and breast cancer risk. Epidemiology 27, 326-333.

Parada Jr., H., et al., 2017. Grilled, Barbecued, and Smoked Meat Intake and Survival Following Breast Cancer. vol. $109 \mathrm{~J}$ Natl Cancer Inst.

Parada Jr., H., et al., 2016. Organochlorine insecticides DDT and chlordane in relation to survival following breast cancer. Int. J. Cancer 138, 565-575.

Pestana, D., et al., 2015. Effects of environmental organochlorine pesticides on human breast cancer: putative involvement on invasive cell ability. Environ. Toxicol. 30, $168-176$.

Raaschou-Nielsen, O., et al., 2005. Adipose organochlorine concentrations and risk of breast cancer among postmenopausal Danish women. Cancer Epidemiol. Biomark. Prev. 14, 67-74.

Rich-Edwards, J.W., et al., 1994. Test of the national death index and equifax nationwide death search. Am. J. Epidemiol. 140, 1016-1019.

Roswall, N., et al., 2018. Organochlorine concentrations in adipose tissue and survival in postmenopausal, Danish breast cancer patients. Environ. Res. 163, 237-248.

Rothman, K.J., et al., 2008. Modern Epidemiology, third ed. Lippincott Williams \& Wilkins, Philadelphia, PA.

Shrier, I., Platt, R.W., 2008. Reducing bias through directed acyclic graphs. BMC Med. Res. Methodol. 8, 70 .

Siegel, R.L., et al., 2018. Cancer statistics, 2018. Ca - Cancer J. Clin. 68, 7-30.

Soto, A.M., et al., 1994. The pesticides endosulfan, toxaphene, and dieldrin have estrogenic effects on human estrogen-sensitive cells. Environ. Health Perspect. 102, 380-383.

Teitelbaum, S.L., et al., 2007. Reported residential pesticide use and breast cancer risk on Long Island, New York. Am. J. Epidemiol. 165, 643-651.

Thongprakaisang, S., et al., 2013. Glyphosate induces human breast cancer cells growth via estrogen receptors. Food Chem. Toxicol. 59, 129-136.

Vighi, M., et al., 2017. Critical assessment of pendimethalin in terms of persistence, bioaccumulation, toxicity, and potential for long-range transport. J. Toxicol. Environ. Health B Crit. Rev. 20, 1-21.

Wang, T., et al., 2018. Pre-diagnostic aspirin use and mortality after breast cancer. Cancer Causes Control 29, 417-425.

Welch, R.M., et al., 1969. Estrogenic action of DDT and its analogs. Toxicol. Appl. Pharmacol. 14, 358-367.

White, A.J., et al., 2013. Exposure to fogger trucks and breast cancer incidence in the Long Island Breast Cancer Study Project: a case-control study. Environ. Health 12, 24

Wolff, M.S., 1999. Half-lives of organochlorines (OCs) in humans. Arch. Environ. Contam. Toxicol. 36, 504.

Wolff, M.S., et al., 2000. Organochlorine exposures and breast cancer risk in New York City women. Environ. Res. 84, 151-161.

Wolff, M.S., et al., 2005. Improving organochlorine biomarker models for cancer research. Cancer Epidemiol. Biomark. Prev. 14, 2224-2236.

Xu, X., et al., 2010. Associations of serum concentrations of organochlorine pesticides with breast cancer and prostate cancer in U.S. adults. Environ. Health Perspect. 118, 60-66.

Zhuang, S., et al., 2012. Distinct mechanisms of endocrine disruption of DDT-related pesticides toward estrogen receptor alpha and estrogen-related receptor gamma. Environ. Toxicol. Chem. 31, 2597-2605.

Zota, A.R., et al., 2010. Self-reported chemicals exposure, beliefs about disease causation, and risk of breast cancer in the Cape Cod Breast Cancer and Environment Study: a case-control study. Environ. Health 9, 40. 